\title{
PNEUMATOLOGIA COMO CARACTERÍSTICA DO SER CRISTÃO: A CONTRIBUIÇÃO DO PENTECOSTALISMO AO CONJUNTO DO CRISTIANISMO
}

Pneumatology as a Characteristic of Being a Christian: the Contribution of Pentecostalism to Christianity as a Whole

David Mesquiati de Oliveira *

RESUMO: O propósito desse artigo é mostrar que a pneumatologia pentecostal pode ser uma importante contribuição para as Igrejas, não tanto por seus enunciados e práticas específicas, senão pelo lugar central que atribui à experiência do Espírito Santo como experiência de Deus. A pergunta que norteou o estudo foi: que possíveis contribuições a pneumatologia pentecostal oferece ao conjunto de igrejas na atualidade? Para responder a este problema, optou-se por destacar os consensos que se construíram no Ocidente sobre o Espírito, desde os traumas com os grupos espiritualistas, passando pelo "esquecimento" e pela apologética racionalista. Na segunda parte focou-se no específico do pentecostalismo como sujeito teológico para, na terceira parte, efetivamente apontar as possíveis contribuições. Sempre que possível, buscou-se dar voz aos teólogos pentecostais para um diálogo teológico.

PALAVRAS-CHAVE: Pneumatologia. Ser cristão. Pentecostalismo. Inculturação da fé.

ABSTRACT: The purpose of this article is to show that Pentecostal pneumatology can make an important contribution to the Churches not so much on account of its statements and practices, but on account of the central place attributed to the experience of the Holy Spirit as an experience of God. The question that governed the study was this: what possible contributions does Pentecostal pneumatology offer

\footnotetext{
* Faculdade Unida de Vitória, Vitória, Espírito Santo, Brasil.
} 
to all the Churches today? In order to answer this question, the author highlights: the consensus of Western theology about the Spirit; the conflicts with spiritualistic groups; the oblivion of the Holy Spirit; the rationalist apologetics. The second part focuses on Pentecostalism as a theological subject. The third part points out the possible contributions of Pentecostalism. Whenever possible, a voice is given to Pentecostal theologians in order to establish a theological dialogue.

KEYWORDS: Pneumatology. Being a Christian. Pentecostalism. Inculturation of faith.

\section{Introdução}

$\mathrm{V}$

amos apresentar traços da pneumatologia pentecostal que, resguardadas as diferentes etapas da inculturação da fé em nossa sociedade contemporânea e as identidades das "diferentes famílias de Igrejas", podem enriquecer o cristianismo global. Os pontos que são compartilhados com as demais famílias cristãs não serão repetidos, deixando espaço para as questões que caracterizam o grupo. Tais intuições brotam de diversas fontes, como dos pentecostalismos sem fronteiras das origens no início do século XX, passando pelo pentecostalismo clássico das Assembleias de Deus no Brasil (autóctone), chegando nas reflexões teólogos pentecostais na academia.

Iniciamos indicando que é preciso considerar que o pentecostalismo moderno não é tão inédito, como possa aparentar. Ele deve ser entendido na esteira de movimentos espiritualistas ${ }^{1}$ históricos, que desde o Pentecostes do Novo Testamento se tornaram uma constante na história da Igreja, ainda que por meio de grupos nas margens. A ênfase no encontro com Deus e a resultante transformação de vida tem sido sempre um alvo e no dizer do teólogo pentecostal Allan Anderson (2019, p. 200), "é isso que aproxima pentecostais e carismáticos ${ }^{2}$ das tradições místicas". Outro elemento importante é que o pentecostalismo é um movimento que busca o reavivamento da Igreja, ele é "essencialmente um movimento religioso (ou "espiritual") com razões religiosas para sua força crescente" (ANDERSON, 2019, p. 214). Terá implicações sociais, políticas e econômicas, mas seu campo de ação é essencialmente o ambiente religioso.

\footnotetext{
${ }^{1}$ Movimento espiritualista como referência às comunidades de fé cristã e aos movimentos na história do cristianismo que tornaram central a experiência com a Terceira Pessoa da Trindade, o Espírito Santo.

${ }^{2}$ Nesse texto tomaremos em conjunto a pneumatologia das igrejas ditas propriamente pentecostais (ênfase no batismo com o Espírito Santo e no falar em línguas) e as Igrejas e movimentos carismáticos, formado por Igrejas "históricas" que apresentam características pentecostais.
} 
Dentre os aspectos essenciais do cristianismo estão a experiência religiosa, a ética, a adoração e a doutrina. Não é fácil determinar com exatidão o que seria mais importante nem formular com precisão e aceitação por todas as famílias cristãs em termos doutrinais os credos, confissões e catecismos. Há distintas ênfases, enunciados e vivências que as separam. Mantendo-se uma disposição para acolhimento das diferenças, é possível um mútuo enriquecimento dos grupos cristãos. Nessa linha, esse texto busca enfatizar aspectos positivos do movimento pentecostal que podem contribuir para o ser cristão, a partir da concepção do Espírito que o grupo sustenta. As diferentes Igrejas poderão avaliar com mais critério em que medida se sentiriam desafiadas por essa pneumatologia pentecostal.

Enfatiza-se a pneumatologia como uma característica do ser cristão. Como disse o teólogo católico Mario de França Miranda (2004, p. 172), "a vida do cristão é essencialmente "espiritual', a saber, conduzida pelo Espírito". E explica: "nossa salvação depende totalmente da ação do Espírito em nós. Deveríamos muito mais captar e seguir os estímulos do Espírito do que cumprir certas práticas que, vistas como 'obras', nos dão a falsa impressão de nos garantirem a salvação". E esse Espírito derramado sobre a Igreja na sua fundação no Pentecostes, é o único Espírito, o que constitui a unidade do corpo de Cristo. Nesse sentido, "todo cristão e todo membro da Igreja é sem mais carismático" (2006, p. 67).

O relatório da 6 $6^{\mathrm{a}}$ fase do diálogo internacional católico-pentecostal (Documento VI) ratifica a dimensão carismática da Igreja, bem como sua constituição pneumatológica. Contra a posição cessacionista, puderam reafirmar os dons espirituais na Escritura e na história da Igreja, como parte do ser Igreja (MAÇANEIRO, 2017). O relatório da $5^{\mathrm{a}}$ fase da mesma Comissão Internacional de Diálogo Católico Pentecostal (2010), discute o "ser cristão", em que as duas tradições cristãs entram em consensos importantes. A análise dos documentos dessa comissão em especial, são lacunas que precisam ser devidamente tratadas nos estudos sobre o pentecostalismo e que, por razões de espaço, não puderam realizar-se neste estudo. ${ }^{3}$

\footnotetext{
${ }^{3}$ As comissões bilaterais de diálogo surgiram dos impulsos do Concílio Vaticano II. A Comissão Internacional de Diálogo Católico-Pentecostal é uma instância oficial de diálogo entre a Igreja Católica e algumas Igrejas Pentecostais. Inicia por volta de 1969-1970 com o então Secretariado Romano para a Unidade dos Cristãos, hoje o Pontifício Conselho para Promoção da Unidade Cristã. Fases do diálogo: $1^{\underline{a}}$ fase (1972-1976): o batismo no Espírito Santo e a iniciação cristã; relação entre Escritura e Tradição; pessoa do Espírito, dons e carismas; $2^{\text {a }}$ fase (1977-1982): a fé, a experiência religiosa e o falar em línguas; o papel de Maria; $3^{a}$ fase (1985-1989): perspectivas sobre comunhão cristã; $4^{a}$ fase (1991-1997): evangelização, proselitismo e testemunho comum; $5^{\text {a }}$ fase (1998-2006): tornar-se cristão: conversão, iniciação cristã, batismo no Espírito Santo e discipulado; 6 ${ }^{\mathrm{a}}$ fase (2010-2016): Carismas na Igreja: significado espiritual, discernimento e implicações pastorais (MAÇANEIRO, 2017, p. 13-14). A 7 $7^{\mathrm{a}}$ fase (2017-2021), foi aberta na sede das Assembleias de Deus dos EUA, em Springfield (Missouri), com o tema "Lex orandi, Lex credendi": relação entre fé, oração (culto) e vida, além da Igreja como meio de graça.
} 
O artigo está dividido em três partes. Na primeira apresenta os consensos que se construíram no Ocidente sobre o Espírito, desde os traumas com os grupos espiritualistas ou do Espírito, passando pelo "esquecimento do Espírito" e pela apologética racionalista. Na segunda parte o foco está no específico do pentecostalismo como sujeito teológico. Na última parte, aponta as possíveis contribuições do pentecostalismo ao conjunto de Igrejas a partir da pneumatologia pentecostal.

\section{O lugar comum da pneumatologia no Ocidente}

Dentre os consensos que se generalizaram na teologia cristã ocidental, ainda que involuntários, sobressai o lugar reduzido da pneumatologia, seja pela influência helenista, pelos traumas com as correntes espiritualistas ou mesmo pelas abordagens ambíguas sobre o Espírito Santo. Esses três elementos serão trabalhados nessa parte.

\subsection{Pneumatologia mínima em um cristianismo racionalizado}

Nos textos neotestamentários o Espírito aparece com destaque, agindo sobre o Cristo, inspirando a Escritura, sondando os mistérios de Deus, apresentando-se como Deus. Acompanhando essa perspectiva "os primeiros Padres da Igreja elaboraram uma cristologia pneumatológica" (MIRANDA, 2004, p. 169). Mas essa tendência não se concretizou. Como afirma Miranda na sequência: "o surgimento da heresia adocionista, que via em Jesus um simples homem, um profeta a mais que recebe o Espírito Santo, fez com que outro modelo cristológico, o da encarnação do Verbo, fosse se impondo cada vez mais". A consequência dessa mudança de modelo gerou "uma certa omissão do papel e da presença do Espírito Santo" (p. 169).

Enquanto outras áreas da teologia recebiam novos impulsos e elaborações, a pneumatologia foi se acomodando a um papel secundário. Durante muitos séculos, sob autoridade de Sto. Agostinho e de Sto. Tomás de Aquino, o papel do Espírito esteve inadequadamente diminuto, conforme pode ser observado na história do cristianismo no Ocidente, em que o relacionamento da Terceira Pessoa da Trindade com a Igreja e com o mundo não era visto como ação própria dele, mas simplesmente apropriado (MIRANDA, 2004, p. 170).

Soma-se a isso as especulações metafísicas da escolástica. Em outro escrito, o referido teólogo afirmou:

Revelação cristã não significa primeira e fundamentalmente um saber sobre Deus, embora tal concepção tenha vigorado muito tempo no cristianismo. Naturalmente a ação salvífica de Deus tem uma dimensão cognitiva. Porém, sob 
a influência do helenismo e da gnose, houve uma intelectualização exagerada dela. Com isto a revelação foi entendida como transmissão de um ensinamento divino que serve à salvação. Daí a preocupação unilateral com as verdades reveladas ou com as formulações da fé, que acaba por gestar um cristianismo racionalizado, cujas consequências sofremos ainda hoje (2001, p. 64-65).

Nesse cristianismo racionalizado, a filosofia grega platônica (metafísica e lógica) se transformou no instrumental teórico que permitia comunicar a experiência da fé cristã no mundo helenizado. Sob essa concepção conceitual, fixaram-se alguns discursos para preservação da verdade doutrinária. A helenização do ensinamento cristão e da linguagem teológica definiu o discurso único sobre a verdade no Ocidente, perseguindo os que diferiam em relação ao enunciado, tratando diferentes casos como "heresia". Esse cristianismo hegemônico, com a pretensão de analisar o "Deus em si", acabou não percebendo que poderia no máximo chegar ao "Deus para nós", como acertadamente já o tinham percebido os próprios místicos medievais e os textos teológicos orantes. A experiência de Deus é na verdade a nossa percepção dele, ou o que de Deus podemos captar a partir da sua revelação. E essa revelação não se dá de forma abstrata, pura ou desencarnada. Antes, a revelação está inculturada, é histórica e encarnada, necessitando sempre ser tematizada/interpretada e de novas inculturações para ser experimentada como ação divina.

De acordo com as diferentes famílias cristãs a revelação se dá em múltiplos lugares (Loci Theologici), tais como: Escritura, Tradição, Magistério, Natureza, História, Cultura, Experiência. O fechamento no cognitivo privou a pneumatologia em particular, e a teologia em geral, de descobrir outras possibilidades, expressões diversas e a necessária criatividade, que pode escapar à explicação racional hegemônica. Do lado ortodoxo, esse efeito foi menor pela forte influência da patrística oriental (EVDOKIMOV, 1996). Do lado católico, é possível constatar: "Naturalmente, essa concepção faz o Espírito Santo desaparecer não só da consciência de fé dos cristãos, mas também do modo como se compreende a si mesma a própria Igreja" (MIRANDA, 2004, p. 169). Do lado protestante, a racionalização seria ainda mais exacerbada, com o biblicismo e a centralidade na pregação (discurso). Um cristianismo racionalizado tem pouco instrumental para lidar com o Espírito, produzindo uma pneumatologia mínima, restrita à economia trinitária funcional e dispersa na teologia. No próximo tópico, busca-se apontar algumas consequências da adoção dessa concepção racionalista e hegemônica.

\subsection{Entre o "esquecimento", a desconfiança e a apologética}

A primeira consequência para a pneumatologia no Ocidente é o que se costuma denominar de "esquecimento do Espírito", que aparece no escasso trato teológico sobre a pneumatologia nos tratados, ainda que no âmbito 
da experiência o Espírito sempre estivesse presente. A opção de "esquecer" o Espírito não passou impune, deixando "consequências negativas nos séculos seguintes" (MIRANDA, 2004, p. 169). Embora a atuação do Espírito Santo na vida cotidiana aconteça de forma discreta e misteriosa, não se pode prescindir de esse agir nem de refletir sobre ele.

Acompanhar a ação do Espírito Santo ao longo da história, discernir corretamente seus desígnios, sintonizar com as expectativas do Povo de Deus e com as diretrizes do magistério não é tarefa fácil, pois exige estudo sério, abertura para o diferente, ultrapassar mesmo que parcialmente o seu próprio horizonte, buscar sinceramente a verdade (MIRANDA, 2013, p. 64-65).

De fato, um "mapeamento" do Espírito não é tarefa fácil. Segundo o teólogo reformado Jürgen Moltmann (1999, p. 13), o "esquecimento do Espírito" na academia durou até as últimas décadas do século passado, quando a curva de inflexão mudou drasticamente. E mais: "com o ingresso das igrejas ortodoxas em 1961 e o ingresso, mais tarde, de algumas igrejas pentecostais no movimento ecumênico, é nestes dois terrenos que estão ocorrendo os avanços na pneumatologia" (p. 16).

A segunda consequência foi uma certa desconfiança em relação aos movimentos que evocavam de forma mais direta o Espírito. Uma panorâmica sobre os movimentos espiritualistas ao longo da história da Igreja mostraria que esses grupos foram tratados com muita desconfiança e estrito controle. Não raras vezes, esses grupos de "entusiastas" foram marginalizados. Algumas das expressões mais conhecidas foram os montanistas, o movimento joaquimita, os anabatistas, os quakers, o movimento holiness e o pentecostalismo. Não se pretende validá-los acriticamente, pois cada um teve sua respectiva limitação. Mas acentua-se o fato de que o isolamento imposto, somado aos excessos de cada um, contribuiu no Ocidente para uma mentalidade mais fechada para o afetivo, para o corporal e para o concreto.

O teólogo católico João Batista Libanio (2002) afirmou que ao longo da história da Igreja no Ocidente houve um "déficit carismático" que atravessou toda a história da Igreja. A resposta viria na forma de "surtos espiritualistas", começando ainda nos tempos do Novo Testamento. Ele registra:

O fenômeno de J. de Fiore e outros surtos espiritualistas à margem da instituição revelaram o déficit carismático que atravessa toda a história da Igreja Católica. As primeiras explosões dessa natureza já aconteceram na Igreja de Corinto e na virada do século II, com o movimento montanista. No primeiro caso, Paulo precisou intervir com firmeza e deixou-nos preciosos capítulos de discernimento dos carismas na Primeira Epístola aos Coríntios (caps. 12-14). O surto montanista significou ponto decisivo de retração diante do carismatismo na Igreja. $\mathrm{O}$ clima carismático existia nos parâmetros traçados por Paulo. Irineu de Lião, que será o grande adversário dos montanistas, reconhece a pluralidade de carismas, recebidos por Deus, no seio da Igreja. São os espirituais. Tal clima carismático transborda com Montano que associa ao carismatismo e messianismo dose de 
espiritualismo antiinstitucional e de desprezo da matéria. Ele encontrou na Frígia campo fértil para tais manifestações, já que lá existiam cultos violentos, emoções religiosas intensas [...] Multiplicaram-se as manifestações extáticas (2002, p. 73, grifos no original).

A repressão aos montanistas combinada com a anterior exortação de Paulo sobre os excessos das manifestações espirituais teria ensejado uma atitude de suspeita na Igreja "que teria ficado traumatizada com a experiência montanista” (LIBANIO, 2002, p. 73). É possível que o caráter antiinstitucional tenha sido a principal ameaça, mas o "trauma" teria se fixado.

A terceira consequência, mais recente, foi o debate apologético acalorado, entre pentecostais de um lado e os cessacionistas de outro. Com transfundo fundamentalista, a discussão girava em torno de quem possuía a melhor leitura, quem estava com a verdade. A questão se perdia na disputa pelos enunciados e na censura das práticas do outro. $\mathrm{O}$ enfrentamento de Lutero na Reforma Magistral do século XVI com os espiritualistas da Reforma Radical, já tinha restringido o Espírito à Escritura e a um lugar controlado (OLIVEIRA, 2017a). Cada uma dessas consequências, à sua maneira, serviu para o empobrecimento da centralidade do ministério do Espírito Santo na vida da Igreja e no mundo.

\subsection{Tendências nas abordagens sobre o Espírito}

Algumas inclinações prevaleceram nas abordagens pneumatológicas do pensamento cristão e que, por razões de síntese e com certa arbitrariedade, classificou-se em quatro grupos: instrumental, extraordinária, coisificação e pragmática.

A fé cristã está baseada na revelação de Deus que se dá em Jesus Cristo, expressa na convicção de que essa revelação definitiva é divina. Em Romanos 8,16 Paulo expressou que "o próprio Espírito testifica com o nosso espírito". Trata-se do testemunho do Espírito (testimonium Spiritus Sancti internum). Apegar-se à essa fase inicial cristológica desloca o testemunho do Espírito a uma obra meramente instrumental, que, apesar da expressa igualdade ontológica na Trindade defendida pelos credos, na prática, mostra-se em uma subordinação funcional. Nessa formulação, a ação do Espírito se tornou "uma obra de instrumentalidade aplicativa" (WILLIAMS, 2011, p. 534). Muitas abordagens sobre o Espírito se concentram nessa fase inicial, reduzindo a obra do Espírito a mera função ou instrumentalidade.

Há uma segunda fase na sequência do Pentecostes que é abertamente carismática e pneumatológica. Não obstante a atuação do Espírito ser fundante para a fé cristã e ter uma obra única e distintiva, nem sempre o Espírito recebe a devida atenção, seja na teologia ou na vida comunitária de fé no cristianismo global. No dizer do teólogo pentecostal Rodman Williams (2011, p. 534), "há um insuficiente reconhecimento de que não 
apenas o Espírito aponta para o Cristo, mas também Cristo, para o Espírito". A atividade do Espírito pode ser percebida em áreas como criação, providência, encarnação, regeneração, santificação, além de sua obra específica sobre a comunidade de fé. A vinda do Espírito Santo é "um dos mais extraordinários e poderosos atos de Deus". E continua: "considerando que a vinda do Espírito é um dom gracioso de Deus, a resposta humana apropriada é recebê-lo. Trata-se de uma dádiva a ser recebida" (WILLIAMS, 2011, p. 511). Uma obra tão extraordinária como a vinda do Espírito não pode ser negligenciada.

O segundo grupo, do extraordinário, tende a ver o Espírito somente relacionado a eventos sobrenaturais ou estritamente religiosos. É um Espírito serviçal da instituição, que age nos limites eclesiais ou no campo do "milagre". É uma possibilidade sedutora nos cristianismos históricos, mas que precisa ser enfrentada por uma adequada concepção do Espírito como aquele que também atua fora dos limites da Igreja, como Espírito de Vida, como o que realiza a vida cristã transformada e como o que empodera (capacita e impele) para viver para o outro.

O terceiro grupo, da coisificação, desfaz a relação pessoal com o Espírito e a converte em uma relação com um objeto ou uma força. O Espírito fica enclausurado em categorias de coisa, disperso nas emoções da vida. Nas abordagens seculares, como no Iluminismo, só havia espaço para um "espírito" moderno. Nas abordagens religiosas, o Espírito seria mais conhecido como "o poder e energia" do que como "Aquele que concede poder e energia".

O quarto grupo, de abordagens pragmáticas, tende a ver o Espírito como uma fonte de poder que capacita para fazer tarefas. Descobre-se a Fonte, busca-se relacionar com o Espírito. A relação com Ele pode adquirir contornos utilitaristas, sob o risco de gerar uma espiritualidade "produtivista", centrada em realizações. Os estudos sobre a teologia pentecostal das últimas décadas têm procurado realçar o lado positivo dessa abordagem pragmática e testemunhal no pentecostalismo, notadamente a partir da exegese pentecostal profundamente lucana.

As abordagens do tipo instrumental, extraordinária e coisificação mostraram-se mais reducionistas, enquanto a do tipo pragmática, desde que a partir de uma relação pessoal com o Espírito, pode ser uma abordagem mais adequada, tendo o Espírito como aquele que impulsiona para o cumprimento da missão e da realização do Reino de Deus.

\section{O lugar elevado da pneumatologia no pentecostalismo}

O final do século XIX e o início do XX testemunhou o surgimento de um movimento que se tornou tema de acalorados debates. Ficou conhecido 
como pentecostalismo, pela ênfase que seus seguidores davam ao Pentecostes neotestamentário, defendendo a atualidade dos dons e milagres no mundo contemporâneo. Essa nova corrente rapidamente se espalhou pelo mundo com numerosos fiéis, tendo adesão de segmentos de outras Igrejas, comumente chamados de carismáticos, como nas Igrejas protestantes tradicionais (1950s.), na Igreja Católica (1967) e na Igreja Ortodoxa Oriental (1967). Nessa parte vamos destacar o específico do movimento pentecostal, sua teologia e características principais, como: a centralidade na espiritualidade, a doutrina pentecostal do batismo no Espírito Santo e a ênfase nas obras do Espírito, como obra única e distintiva.

\subsection{A centralidade da espiritualidade}

O teólogo pentecostal Steven Jack Land (1993) defende acertadamente que o ponto de partida da teologia pentecostal é sua distintiva espiritualidade. Como os demais movimentos religiosos restauracionistas, o pentecostalismo toma como centro o Pentecostes carismático do Novo Testamento e enfatiza duas características do período apostólico, que na linguagem de Land seriam: apocalyptic affections e eschatological hunger. O primeiro daria o tom da espiritualidade carismática pentecostal e o segundo, o sentido de urgência e de transformação. Nessa linha, os primeiros anos do pentecostalismo não foram sua infância, mas o coração do movimento, perceptível em sua paixão por Deus e por seu reino, vivido na antecipação (primícias) pelo Espírito. Kenner Terra (2020), entre outros teólogos pentecostais, faz uma importante análise da epistemologia pentecostal, que amplia esse debate.

Alinhado com Land (1993), o carismático e reformado James K. A. Smith (2003, p. 114), indica que a teologia e experiência religiosa pentecostal poderiam ser descritas como uma "epistemologia do afeto", para além da racionalidade que imperou no cristianismo ocidental. Terra (2020, p. 52) explica que não é uma irracionalidade, mas uma nova racionalidade em que há espaço para "o sobrenatural instaurador, as expressões vivas do amor e pathos da experiência do Espírito, conjugando o intelecto e vibração das emoções". Esse tipo de racionalidade "poderia ajudar na categorização e o equilíbrio entre intelecto, afetividade, emoções e experiência". Essa forma de pensar pode ser uma contracultura intelectual, pois

para a teologia pentecostal a relação imediata da ação e presença divinas coloca o saber teológico no nível da relação direta e sem mediação racionalista conceitual, ainda que a ortodoxia tenha seu lugar, seja importante e se estabeleça nessa relação dialética entre fé experiencial e fé conceitual. A ortodoxia afetiva seria, nesse sentido, o saber sobre Deus eivado pelas afeições da alegria, dor, carisma, milagre, batismo no Espírito, no sentimento limite do "já ainda não" preste ao fim, a saber, no corpo e a partir do lugar da vida do fiel (TERRA, 2020, p. 53). 
Allan Anderson (2019, p. 199) afirmou que "todas as várias expressões do pentecostalismo têm uma experiência em comum: um encontro pessoal com o Espírito de Deus que empodera e capacita as pessoas para o culto [...] evidências certas de 'Deus conosco'". E continua: "a experiência da plenitude do Espírito é o coração da teologia pentecostal e carismática" (p. 209). Para alcançar essa intensidade na relação com Deus os pentecostais e carismáticos dedicam-se à oração. E como bem expressou Miranda (2004, p. 242), “a oração não é uma atividade piedosa situada ao lado da própria atitude fundamental. Observada com atenção, a oração brota da vivência cristã e dela recebe todo o seu sentido". A partir da oração modelo de Jesus, Miranda (2004, p. 244) concluiu: "a oração excelente é a que brota da liberdade, constituindo um ato de entrega e de amor ao outro".

Na espiritualidade pentecostal, a oração é também um estado de espírito, uma vida ressignificada a partir da presença do Espírito. É possível falar em estado de êxtase permanente, diferenciando de transes específicos. No êxtase há consciência sobre o que se faz, embora a pessoa esteja sob a influência de uma experiência religiosa mais intensa. No pós-Pentecostes, a experiência do Espírito lançou a Igreja para o mundo, para a vida, para a missão (OLIVEIRA \& TERRA, 2018). O teólogo de tradição batista Harvey Cox (1995) entende que a espiritualidade pentecostal é uma resposta ao "déficit de êxtase" do cristianismo do século XX.

A espiritualidade pentecostal é holística, pois nesse "encontrar Deus", a experiência do Espírito permeia a pessoa inteira. Anderson (2019, p. 216) registra que "a grande atração da espiritualidade pentecostal é que ela afirma proporcionar respostas para problemas existenciais no mundo todo". E mais: "os projetos comunitários amplos e o envolvimento significativo em organizações políticas e cívicas e em sindicatos, representam uma espiritualidade nova e vigorosa que oferece ajuda para problemas humanos" (p. 215). O teólogo pentecostal chileno Juan Jacobo Tancara Chambe (2011, p. 249), depois de um amplo estudo sobre o pentecostalismo popular na Bolívia e América Latina afirmou: “Tantas prácticas y pensamientos pentecostales son inspirados por el deseo de ser libre o el de conformar otro mundo, sin discriminación ni exclusión". E continua: "Muchas personas anhelamos el pentecostés del principio, la pentecostalidad, que es incluyente, sensual, irreducible a una institución eclesial, a una teología, a un dogma, a una religión en particular". Ainda de acordo com este autor:

El Espíritu se hace presente de muchas formas, aparece en las religiones, pero también en las obras de arte; en las sociedades, en los movimientos populares, en el movimiento obrero o indígena; en las rebeliones juveniles, especialmente en cada ser humano. El Espíritu nos "arrebata", nos saca desde nuestras particularidades intrascendentes/pecadoras hacia la universalidad; desde nuestra finitud hacia lo infinito; somos seres finitos atravesados por la infinitud. La 
experiencia con el Espíritu hace estallar cualquier concepto y sugiere: "libertad", "amor", "política", "renacimiento", "ternura", "búsqueda", "cuerpo", "misticismo", "rebelión", "poesía”, "vida nueva"... (TANCARA CHAMBE, 2011, p. 253).

Assim, a espiritualidade pentecostal retoma o mais básico da experiência religiosa cristã, o encontro com Deus, para interpenetrar físico e espiritual, pessoal e social. Há uma prioridade para o "saber intuitivo, performático, poético, pneumático, extático, em suma, experiencial" (OLIVEIRA \& TERRA, 2018, p. 18). Na força do Espírito a fé vivida torna-se realidade dinâmica, criativa e irradiante.

\subsection{O batismo no Espírito Santo}

A pergunta é: como os pentecostais entendem ser possível a nova vida no Espírito? A resposta passa pela principal doutrina pentecostal: o batismo no Espírito Santo. Esse tema é tão importante que recebe um capítulo especial nas teologias sistemáticas pentecostais (HORTON, 1997; GILBERTO, 2008; WILLIAMS, 2011) e nas declarações de fé de suas diversas igrejas. Antonio Gilberto (2008), pastor da Assembleia de Deus, afirma que o batismo no Espírito

É um revestimento e derramamento de poder do Alto, com evidência física inicial de línguas estranhas, conforme o Espírito Santo concede, pela instrumentalidade do Senhor Jesus, para o ingresso do crente numa vida de mais profunda adoração e eficiente serviço para Deus (Lc 24,49; At 1,8; 10,46; 1 Co 14,15.26) (GILBERTO, 2008, p. 191).

O batismo no Espírito Santo para os pentecostais não é imersão no corpo de Cristo, nem regeneração ou santificação. Junto com as demais tradições cristãs eles afirmam que "todo cristão recebe o Espírito vivificador e habitador. Não há cristão sem o Espírito” (MENZIES, 2016, p. 53). Mas diferem ao interpretar a forma como se dá a vinda do Espírito sobre as vidas de homens e mulheres que seguem a Cristo: o batismo com o Espírito "es una experiencia definitiva, posterior a la salvación, en la cual la tercera persona de la deidad viene sobre el creyente para ungirlo y energizarlo a favor de un ministerio especial" (DUFFIELD \& VAN CLEAVE, 2002, p. 199). A declaração de fé das Assembleias de Deus (2017, p. 165) afirma: "Trata-se de uma experiência espiritual que ocorre após ou junto à regeneração, sendo acompanhada da evidência inicial do falar em outras línguas. Para as correntes clássicas do pentecostalismo, "falar em línguas", glossolalia (línguas extáticas, diferente da xenolalia), é fundamental (McGEE, 2017; GILBERTO, 2019; WYCKOFF, 1997; ROBECK JR., 2017).

Os teólogos pentecostais Duffield \& Van Cleave (2002, p. 197) apontam que o batismo pentecostal "es de vital importancia en la relación con la vida espiritual y el servicio de todo creyente. El bautismo con el Espíritu Santo es el secreto del poder en la Iglesia. Es la mayor necesidad en toda 
esfera de actividad cristiana". Fica estabelecida a íntima relação entre o espiritual e o físico, entre a experiência religiosa e a vida social, entre teologia e missão. Tancara Chambe (2011) apresenta um quadro vívido da experiência pentecostal:

Cuando el Espíritu nos bautiza, tomamos nuestra libertad y nos hacemos cargo de ella, redescubrimos entonces nuestro poder. Sentimos que no tenemos por qué delegar el poder a nadie, ni hipotecar nuestra libertad a determinado sistema económico, social o político (1Co 7.23) ni a determinadas personas. El Espíritu nos hace libres (libres para servirnos los unos/as a los otros/as, para amarnos). [...]. El bautismo del Espíritu, que provoca la desinhibición del cuerpo, nos recuerda que el cuerpo es para la libertad, para la recreación y el placer (TANCARA CHAMBE, 2011, p. 249, 251).

A doutrina do batismo pentecostal defende: “O Espírito de Pentecostes é, na realidade, o Espírito para os outros, o Espírito que impele e capacita a igreja para levar as 'Boas Novas' de Jesus a um mundo perdido e agonizante. É essa perspectiva lucana e missiológica que molda o entendimento pentecostal do batismo no Espírito Santo" (MENZIES, 2016, p. 53). Alguns estudos sobre o batismo pentecostal, como do teólogo luterano Uwe Wegner (2006) e do pentecostal Craig Keener (2018b), apresentam uma tratativa mais imparcial, destacando aspectos positivos e negativos. Os estudos dos teólogos pentecostais Anthony Palma (2014), Menzies \& Menzies (2002), McGee (2017), Ruthven (2017), Gilberto (2008, 2018), Macchia (2006) entre outros, são de pentecostais que enfatizam a validade dessa doutrina. $\mathrm{Na}$ última parte deste artigo será analisado como essa concepção carismática pode ser uma contribuição para o cristianismo mais amplo. Por agora, o foco estará na obra específica do Espírito, revalorizada pelos pentecostais e carismáticos.

\subsection{O Espírito e sua obra única e distintiva}

O teólogo pentecostal John Wyckoff (1997, p. 431) faz um comparativo sucinto entre as posições católica, protestante e pentecostal, a fim de evidenciar a diferença de posturas. Os católicos enfatizariam mais o papel da Igreja e dos sacramentos, acabando por subordinar de alguma forma o Espírito à Igreja; os protestantes, o papel da pregação e da fé, subordinando o Espírito à Bíblia. Os pentecostais, por sua vez, seriam uma reação aos dois primeiros: "ao sacramentalismo que pode se tornar mecânico e à ortodoxia biblista que pode se tornar espiritualmente morta - reclamam [os pentecostais] uma experiência vital com o próprio Deus no Espírito Santo" (p. 432).

Os dois primeiros, católicos e protestantes, enfatizam a obra do Espírito em conjunto com o Cristo, em termos soteriológicos. Os textos paulinos ganham notoriedade. Os pentecostais, sem negar aquela obra do Espírito, focaram na relação do Cristo com o Espírito, e nas obras próprias do 
Espírito, em termos missiológicos e de vida cristã. Os textos lucanos aqui sobressaem. Afirma Williams (2011, p. 535): “De fato, esse posterior ato de mediação, do Pai por intermédio do Filho, é o ato apoteótico do envio do Espírito Santo". E continua: "Devemos ser muito agradecidos pelo fato, na renovação espiritual contemporânea, de o Espírito Santo estar sendo reconhecido pela sua obra única e distintiva". Esse redescobrimento do Espírito é por vezes chamado de centralidade do Espírito, mas não seria um termo correto. Mais adequado seria apontar a retomada do equilíbrio ou circularidade entre uma cristologia pneumatológica e uma pneumatologia cristológica. A pneumatologia pentecostal faz aqui uma importante contribuição (KARKKAINEN, 2002; YONG, 2005).

O Espírito aponta para o Cristo e o Cristo aponta para o Espírito. No primeiro temos o papel do Espírito para a salvação, no segundo sua atuação pentecostal, no seguimento do Pentecostes. Os pentecostais chamaram essa concepção de "evangelho pleno" ou "evangelho quádruplo": Jesus salva, cura, batiza no Espírito Santo, e breve voltará (DAYTON, 2018). É a atuação do Espírito enviado pelo Pai por intermédio do Filho.

A mensagem do Evangelho pleno proclama a centralidade da obra do Espírito Santo como o Agente ativo da Trindade na revelação que Deus fez de si mesmo à sua criação. A mensagem do Evangelho pleno diz que Deus hoje continua a falar e a agir, como nos tempos do Antigo e do Novo Testamento. [...]. A única maneira de se conhecer uma pessoa, inclusive o próprio Deus, é saber o que ela tem dito e feito. A Bíblia nos conta o que Deus tem dito. E a obra contínua do Espírito Santo nos revela o que Ele continua a dizer e fazer hoje (McLEAN, 1997, p. 383, 385).

Moltmann (1999) também percebeu que o espírito é o sujeito da palavra, e por isso vai mais longe que a palavra, tanto quanto for possível a própria realidade sensível: “O Espírito de Deus é mais do que apenas o manifestar-se de sua revelação no homem, e mais do que apenas o fato de a palavra anunciada ser acolhida com fé no coração do homem". E continua: "Pelo contrário, o Espírito leva as pessoas a um novo início de vida, tornando-as os próprios sujeitos de sua nova vida na comunidade de Cristo" (p. 14). Com isso, as pessoas estão experimentando o Espírito Santo na comunidade, mas, sobretudo, interiormente, como experiência religiosa profunda. O Concilio Vaticano II, por meio da Gaudium et Spes (GS) já tinha afirmado ousadamente: “Devemos admitir que o Espírito Santo oferece a todos a possibilidade de se associar, de modo conhecido por Deus, ao mistério pascal" (GS, n. 22).

Uma observação importante vem de Miranda (2004, p. 185): “a ação do Espírito em nós nunca deve ser buscada por si mesma, como uma meta. A meta é sempre o próximo (Deus). Pois essa ação nos impele para fora de nós mesmos em direção ao outro". E continua: "a experiência da ação salvífica do Espírito nada tem de um hedonismo espiritual, mas representa 
apenas o lado experiencial da atitude fundamental cristã [...] a dimensão mística intrínseca à aventura cristã" (p. 186). Temos assim, a diligência para harmonizar a experiência, a mística, o Cristo, o Espírito, a Revelação e a vida cristã.

\section{Contribuições do pentecostalismo às igrejas}

No final da parte anterior já estavam implícitas algumas contribuições do movimento pentecostal ao conjunto das igrejas. Não só o Espírito aponta para o Cristo, mas o Cristo também aponta para o Espírito, o que nem sempre foi devidamente refletido. Nesta parte queremos destacar outras possíveis contribuições do pentecostalismo às igrejas, sem, com isso, invisibilizar as potenciais contradições que toda concretização histórica da fé apresenta. Uma pneumatologia integral é parte constitutiva do ser cristão. Isso será aprofundado com relação à dimensão sobrenatural da fé na vida cristã, à missão e à ampliação dos que fazem teologia: leigos, homens e mulheres, pobres, entre outros.

\subsection{Retomar a dimensão sobrenatural da fé}

Frente a um cristianismo racionalista, assegura-se o caminho da afetividade, do sentimento, das metáforas, das narrativas, enfim, da experiência como lócus revelacional (OLIVEIRA \& TERRA, 2018). A dimensão mística adquire contornos vivenciais no cotidiano do cristão e da Igreja. Nas palavras de um dos pioneiros do pentecostalismo moderno, o pastor da igreja na Rua Azusa nos idos de 1906, William Seymor (2001, p. 36), "cada filho de Deus deve buscar o seu pentecostes pessoal". Com tamanha capilaridade e profundidade, a experiência pneumatológica de Deus irrompe na existência humana, permitindo apreciar o milagre sem banalizá-lo. É possível falar em uma hermenêutica do Espírito, uma forma de ver o mundo sob ação direta do Espírito (CAMPOS, 2018b; KEENER, 2018a e 2018b, OLIVEIRA \& TERRA, 2018).

Como bem afirmou Kenner Terra (2020, p. 53), "para a teologia pentecostal a experiência não é qualquer coisa, mas a ação do Espírito como foi realizada entre os apóstolos e as comunidades cristãs primitivas". Essa dimensão experiencial e mística da fé como lócus da compreensão pentecostal é uma retomada da riqueza da experiência religiosa das primeiras comunidades cristãs, conformando uma epistemologia afetiva (SMITH, 2003).

O teólogo pentecostal peruano Bernardo Campos (2018a) propôs o princípio da pentecostalidade, tomando o Pentecostes como modelo e normativo para a Igreja, abordagem clássica do pentecostalismo. A pentecostalidade 
seria a presença do Espírito, “aquela experiência universal que expressa o acontecimento de Pentecostes em sua qualidade de princípio ordenador da vida" (p. 105). E continua:

Desde que cunhamos a palavra Pentecostalidade, a entendemos como um critério epistemológico para falar da vocação de universalidade da igreja e, como categoria que permitiria superar as aporias da nova, mas precária, historização e institucionalização dos Pentecostalismos, ao mesmo tempo que uma notae (característica) da igreja (CAMPOS, 2018a, p. 105).

Os pentecostalismos seriam realizações históricas desse princípio da pentecostalidade, mas não se confundem com ele, uma vez que o Espírito foi dado a toda Igreja. Tancara Chambe (2011, p. 250) esclarece: “Ningún pentecostalismo es dueño del Espíritu, son más bien expresiones del Espíritu, y lo son en tanto y cuanto mantengan en sus prácticas y principios la solidaridad/reciprocidad, la reproducción de la vida en comunidad".

A pentecostalidade não é a pentecostalização da Igreja. Tem a ver com assumir a ação do Espírito de maneira ativa na igreja e na teologização, mais do que as formas clássicas de Espírito do Filho ou da força (energia) de Deus. Sua pessoalidade divina é estimada, invocada e presente. A escolha desse termo pelo teólogo pentecostal peruano não tem a ver com os pentecostais de maneira direta, mas com a forma como o Espírito agiu no período do Pentecostes, na igreja dos começos. Essa teologização aberta sobre o Espírito Santo é assumida sem rodeios, sem uma hierarquia dentro da Trindade, como muitas vezes resultam algumas abordagens trinitárias. O princípio pentecostalidade "é a força do Espírito que outorga poder ao ser humano para superar os condicionamentos que querem reduzi-los à desumanização" (OLIVEIRA, 2017b, p. 550).

Os pentecostalismos substituíram a mediação do discurso evangélico e a formalização dos ritos por um imediatismo na relação sensorial com o sagrado. O místico/emocional prevalece sobre o institucional. A intermediação do sagrado via discurso teológico é preterida para dar espaço a uma relação imediata que resulte em experiências do Espírito (valorização do transe e do êxtase) (OLIVEIRA, 2017c). A espiritualidade pentecostal estaria mais próxima da pneumatologia do Oriente, como indica Land (1993, p. 29), em sua compreensão de espiritualidade como perfeição e participação na vida divina (theosis), ressaltando as figuras de Gregório de Nissa, Macário do Egito e Santo Simão, o Novo Teólogo. Paul Evdokimov (1996), teólogo da Igreja Ortodoxa, fala da pneumatologia oriental em termos de embriaguez, renunciando às expressões habituais que tratam do Espírito, aquele que "é o único a não ter a sua imagem numa outra Pessoa, ele é essencialmente misterioso" (p. 87). E acrescenta: "A sua missão terrestre de ser Fonte inesgotável dos dons e carismas, de santificação e de santidade, incita os Padres a distinguirem entre o dom, a graça e o Doador da graça, a Pessoa do Santo Espírito, e eis por que, para o Oriente, o Espírito Santo 
não fica reduzido a ser o vínculo entre o Pai e o Filho" (p. 90). Na mesma linha, o teólogo pentecostal chileno reflete:

Pentecostalidad, antes que razón es pasión, antes que prosa es poesía, antes que $\log o s$ es balbuceo o glosolalia; un regreso a la palabra original, a la que fundó y re-fundará el mundo. Y antes que palabra es cuerpo, lágrima, sudor, sed y hambre de pan y justicia, risa, canto, danza, borrachera (que sustituye a la borrachera superficial que se logra con el vino o cerveza). -“No hace falta estar alcoholizado para estar borracho"-, desinhibición del cuerpo; liberación concreta (TANCARA CHAMBE, 2011, p. 253).

A vida cristã cheia (dirigida) pelo Espírito produz liberdade e plenitude, ampla libertação (ALVAREZ, 1992). A espiritualidade dos pentecostalismos é uma expressão da fé cristã, e como tal, um passo importante no processo de inculturação da fé. Uma fé mística, comunitária e pública, retomada a partir dos carismas na comunidade, do empoderamento simbólico dos seus membros, da vida como culto a Deus e como serviço ao outro, numa circularidade humanizadora dinamizada pelo Espírito.

\subsection{O Espírito na missão}

Não é de estranhar que essa espiritualidade e concepção pentecostal impulsione um ardor missionário e pastoral nas comunidades. A irradiação da fé como impulso para a transformação assumiu várias dimensões (anunciar, testificar, servir, comunicar-se, partilhar, interpelar, educar e transformar) a partir de uma missão que se viu como missão do Espírito de Deus (Missio Spiritus sancti) e não da Igreja, que reconheceu em Deus a iniciativa, o poder para executá-la e a glória pelos resultados. Também é digno de nota que a urgência missionária no pentecostalismo tem a ver com sua perspectiva escatológica, da crença na volta iminente de Cristo na forma de arrebatamento, instaurando uma realidade apocalíptica. Fato é que sob a liderança do Espírito Santo, a missão ganhou contornos prioritários, embora, como toda tematização histórica, tenha suas limitações.

A presença do Espírito atua na dimensão do anúncio, indicando o conteúdo, que é o dom de Deus em Jesus como boa notícia, como aquele que é dado ao mundo para reconciliação. $\mathrm{O}$ ardor missionário, com ênfase na decisão pessoal dos ouvintes tem levado milhões de pessoas a uma vida cristã fervorosa (BONINO, 2003, p. 126s.). O risco tem sido o conversionismo/proselitismo. A dimensão do testemunho empodera o cristão e a Igreja para dar testemunho, mas, sobretudo, para ser testemunha (gr. mártyras, "mártir do evangelho"). Trata-se de um envolvimento pessoal e existencial com a missão. Ser testemunha do evangelho é ir além do ato de testemunhar da fé, porque faz mais do que "falar sobre", há uma irradiação da fé e da presença do Espírito por meio de uma vida cristã coerente com os valores do Reino. A crítica em termos gerais é que, a 
Igreja como instituição "ao invés de constituir-se portadora e testemunha do Evangelho, ela se apresentou como 'defensora' do Evangelho. Isto na prática se refletiu num esforço de domesticar o Evangelho" (NIEBUHR, 1967, p. 17).

O mesmo Espírito impele ao serviço, à dimensão diaconal, que faz com que a comunidade atue no atendimento ao outro tendo como base a fé cristã, o cuidado primordial de Deus por sua criação, demonstrado na promessa de redenção. O serviço tem como colunas o engajamento na assistência ao necessitado e o cuidado integral. $\mathrm{O}$ problema reside em instrumentalizar o serviço como mero meio evangelizador, quando a diaconia, o cuidado do outro, é, em si, missionário, no seguimento de Jesus. Outra dimensão missional potencializada pelo agir do Espírito é a capacidade de comunicar-se, pelo uso de linguagem adequada/inculturada e pela efetiva convivência de caminhada com os pobres, que permitem entrar em diálogo e ter comunhão mais profunda. Participando dos anseios do mundo e tendo uma abordagem mais holística, a fé torna-se mais presente. A quantidade de pequenas congregações e a vida comunitária partilhando angústias e limitações, especialmente nas periferias do mundo, tem sido um meio eficaz de comunicação.

A dimensão da partilha tem como característica a capacidade de dar-se e de aceitar o outro. Ao dar-se na gratuidade e na verdade, os cristãos dirigidos pelo Espírito experimentam o basilar da vida espiritual, a descentralização de si mesmo para ir em direção ao outro. Ao aceitar o outro do jeito que ele é, na confiança e com acolhida profunda, experimenta-se a simbiose da reciprocidade, que nos torna humanos, ao perceber que não podemos ser sem o outro, que o outro faz parte do nosso existir. A reciprocidade é anterior à ética, é um ato existencial de acolhida do outro como parte da nossa existência. Partilhar, missiologicamente, é doar a si mesmo e aceitar o outro, como parte da sua existência, fraterna e sororal, dinamizada pelo Espírito.

Mas o Espírito não age apenas nos indivíduos e internamente, também atua institucional e socialmente, por meio das dimensões interpelação, educação e transformação. Interpelar diz respeito à capacidade profética da Igreja e dos cristãos, de denunciarem, enfrentarem e desafiarem as estruturas injustas da sociedade. "A Igreja, no seu papel profético, é a guardiã que revela as estruturas dinâmicas da sociedade e se opõe a seu poder demoníaco, revelando-o, mesmo quando dentro dela. Ao assim fazer, a Igreja ouve, também, as vozes proféticas fora dela, que julgam a cultura e a ela mesma como sua parte" (TILLICH, 2009, p. 92).

É preciso uma pedagogia para agir no mundo, uma metodologia dialogal e conscientizadora, que eleve seus interlocutores à condição de sujeitos da sua própria história, uma pedagogia da autonomia, libertadora. Na missão, 
a metodologia também é conteúdo, o jeito de se comunicar também carece do amor que se pretende compartilhar, é disso que se trata a dimensão da educação. E por último, até como consequência das outras ações, temos a dimensão da transformação, que inclui conversão, libertação e crescimento. Isso não quer dizer que a Igreja tenha o poder de transformar a sociedade, mas de ser um instrumento para isso. A Igreja

não tem o poder de delinear estruturas sociais perfeitas nem de sugerir reformas concretas. Mudanças culturais ocorrem impulsionadas pela dinâmica interior da própria cultura. A Igreja participa nelas, às vezes, liderando, mas sempre como força cultural entre outras e não como representante da nova realidade histórica (TILLICH, 2009, p. 91).

O Espírito na missão age conferindo ousadia. O teólogo reformado David Jacobus Bosch (2007, p. 615) conclui que na obra lucana, "o Espirito Santo é o Espírito da ousadia (parresia) em face da adversidade e da oposição. A igreja prossegue a missão de Cristo no poder do Espírito. É capacitada a efetivar o amor de Deus em seu dia-a-dia e em que a justiça e a retidão se tornem presentes e atuantes". Retomar essa ousadia missionária é indispensável, atuando com equilíbrio nas várias dimensões missionais no seguimento de Jesus no poder do Espírito.

\subsection{Ampliação dos sujeitos do fazer teológico}

Outra contribuição fundamental do pentecostalismo está em sua descentralização no labor teológico, incluindo um sem número de sujeitos no processo. Graças ao valor da experiência como lugar teológico e à consequente descentralização do acesso a Deus há uma relativização da ordem institucional e do "centro", permitindo um florescimento nas "margens" (OLIVEIRA \& ROCHA, 2018). O acesso não mediado a Deus relativiza os mediadores sacramentais e litúrgicos a partir da experiência interior (COX, 1995, p. 87). Essa via de acesso direto a Deus foi acionada pelos cristianismos das origens, pelos grandes místicos medievais e pelos espiritualistas da reforma radical do século XVI, como exemplos. Se cada crente está vivendo um "pentecostes pessoal" atualizado em seu contexto, um governo pneumatológico estará manifesto, tendo a descentralização como marca institucional, em que o Espírito capacita pobres, homens e mulheres, clérigos e leigos (ROCHA, 2008, p. 148s.). A comunidade é co-sujeito do labor teológico no poder do Espírito e leitura das Escrituras, formando a tríade hermenêutica Espírito-Palavra-Comunidade (ARCHER, 2004; YONG, 2006). Repare a ênfase dos pioneiros pentecostais: “Em cada assembleia, a primeira coisa a ser verificada é se o Espírito Santo está empossado como Presidente [...]. Não que seja errado haver um homem na direção, mas tal indivíduo deve estar cheio do poder do Espírito" (SEYMOR, 2001, p. 137). 
Uma das consequências dessa comunidade carismática é a releitura do "sacerdócio universal", relativizando as categorias leigo/clero. A evolução do ministério ordenado, que já no século I tinha aparecido como como fiador da tradição apostólica, gerou uma classe de ministros ordenados que assumiu uma posição dominante. "A clericalização da igreja acompanhou pari passu a sacerdotalização do clero" (BOSCH, 2007, p. 559). De um lado o clero com papel ativo, capacitado para o agir, e de outro o "laicato (de laos, 'povo [de Deus]'), sendo que se entendia a este como imaturo, menor de idade e inteiramente dependente do clero em questões religiosas" ( $p$. 559). Desde o último século, no entanto, o protagonismo dos leigos está em franca expansão: "o movimento que conduz do ministério como monopólio de homens ordenados para o ministério como responsabilidade de todo o povo de Deus, ordenados ou não, constitui um dos mais dramáticos câmbios a ocorrer na igreja hodierna" (p. 558). O teólogo batista Alessandro Rocha constatou:

O pentecostalismo gerou uma nova perspectiva teológica em que o Espírito é quem capacita os agentes religiosos para as diversas funções na igreja. A novidade daquele movimento estava, porém, na condição desses agentes. Operários negros, mulheres e crianças foram se constituindo protagonistas na pregação e vivência eclesial do evangelho (ROCHA, 2008, p. 150).

Mas essa abertura não pode ser em termos de "concessão" da hierarquia de plantão, que pode, com isso, estabelecer os limites claros da "intromissão" dos novos agentes. A radicalização do sacerdócio universal propicia o surgimento de novos atores eclesiais, com voz e ação, ampliando a capacidade criativa da Igreja de lidar com a conjuntura contemporânea. Cada crente se vê na condição de entender a fé e na incumbência de assumir responsabilidades na comunidade. Uma ousadia no Espírito para ler as Escrituras em comunidade e agir a partir daí (ARCHER, 2004).

A leitura da Bíblia em chave comunitária e dinamizada pelo Espírito a partir da experiência é uma potencialidade do pentecostalismo para superar a leitura bíblica fundamentalista:

São duas maneiras de viver a Bíblia: para o fundamentalismo, ela é um testemunho objetivo, em alguma medida externo, que 'está aí. O pentecostal, no dizer de Campos 'sente-se parte do texto, renarra a Bíblia, sente uma congenialidade com o texto' que lhe permite atualizá-lo, revivê-lo em sua situação, prolongá-lo. Na tradição teológica ela tem sido chamada de 'interpretação espiritual', tendo assumido diversas formas e ocupado um lugar importante na vida da igreja [...] Mas quão mais rica poderiam ser a experiência, a prática e a leitura sem o lastro de um esquema hermenêutico que muito pouco tem a ver com a identidade real da experiência e da fé do crente! (BONINO, 2003, p. 71-72).

Com a acolhida da ação direta do Espírito Santo a comunidade de irmãos e irmãs transforma-se em uma comunhão de livres e iguais (MOLTMANN, 
2002, p. 34). Essa democratização e descentralização tem consequências teológicas. Em tom ousado e muito crítico Jürgen Moltmann questiona:

será que uma igreja que ordena exclusivamente homens ao ministério e exclui as mulheres da proclamação, da profecia, possui o Espírito Santo, ou será que ela o 'abafa', reprimindo sua ação libertadora? [...] O Espírito de Deus não respeita as diferenças sociais. Pelo contrário, abole-as. No cristianismo, todos os movimentos de avivamento cheios do Espírito perceberam e disseminaram os elementos de revolução social da experiência do Espírito (2002, p. 34).

A inevitável institucionalização do movimento pentecostal tem procurado domesticar esse pluricentro teologal e participativo, especialmente por conta do caráter revolucionário de um sacerdócio que se dê não em termos de privilégios e autoridade, mas de serviço e de cooperação. Em hipótese alguma sugere-se a supressão da liderança formal da Igreja em nome de um comunitarismo eclesial anárquico. O Espírito também atua nas estruturas, apesar de transcendê-las. $\mathrm{O}$ mais importante aqui é redescobrir o apostolado dos leigos, a vocação e contribuição de cada cristão ao corpo de Cristo, à comunidade e ao mundo. Em lugar de estruturas rígidas e burocráticas, mais igualitarismo e vida comunitária.

\section{Conclusão}

O pentecostalismo é um movimento que se caracteriza pela busca de restauração das origens do cristianismo neotestamentário, tomando o evento de Pentecostes e a operação apoteótica do Espírito Santo como normativos para a Igreja. Essa radicalidade (lat. radicalis, "volta às raízes"), foi possível a partir da retomada da experiência como Loci Theologici intencionalmente animada pelo Espírito, em uma circularidade entre Espírito, Comunidade e Escritura. O necessário equilíbrio entre o Espírito de Cristo (soteriologia) e o Cristo que aponta para o Espírito (missiologia e vida cristã) tem sido uma força criativa e vigorosa do movimento.

O desenvolvimento de uma comunidade carismática informada pelo Pentecostes despertou dons e agentes religiosos os mais diversos, ativando um ardor missionário impelente.

Promoveu uma certa democratização dos ministérios e ativação de dons; ajudou a combater a segregação racial; dignificou os pobres e marginalizados; e, melhorou a auto-estima das massas. Resultou em uma maior participação dos leigos, ao criar estruturas paralelas de poder e de serviço (OLIVEIRA, 2017c). Ofereceu acesso não mediado a Deus por meio de uma pneumatologia carismática que resultou em valorização da afetividade e partilha comunitária. 
O movimento pentecostal pode oferecer à igreja mundial mais que uma experiência religiosa e fervor espiritual: há doutrina e teologia também. Alguns avanços estão no novo olhar para Lucas-Atos, não subordinando a teologia à perspectiva paulina, além da natureza missiológica do discipulado e da Igreja, recordando sua vocação apostólica no poder do Espírito. Coloca-se em evidência, por meio da espiritualidade pentecostal, as experiências do Espírito Santo na atualidade, sua importância e significância simbólica. Nesse sentido, até os sacramentos são ressignificados, pois como afirmou o teólogo pentecostal Robert Menzies (2016, p. 115), o falar em línguas passa a ser um "sacramento" dos (e para os) pentecostais. Além disso, Anderson (2019, p. 211) percebe que a teologia pentecostal é "uma teologia vinda de baixo e uma teologia das pessoas".

A espiritualidade pentecostal pode ser inculturada de diversas formas. Como uma expressão da fé, tem elementos dinâmicos e criativos. Destacam-se o lugar da experiência de Deus, a retomada do sobrenatural da fé, as dimensões missionais no seguimento de Jesus no poder do Espírito e a ampliação dos agentes religiosos "cheios do Espírito", dinamizando a vida e o labor teológico. As intuições do movimento pentecostal em diálogo aberto com as famílias cristãs de longa tradição (Oriente e Ocidente) permitem novos impulsos e aprofundamentos na pneumatologia.

\section{Referências}

ÁLVAREZ, C. E. (Ed.). Pentecostalismo y liberación: una experiencia latinoamericana. San José, Costa Rica: DEI, 1992.

ANDERSON, A. H. Uma introdução ao pentecostalismo: cristianismo carismático mundial. São Paulo: Loyola, 2019.

ARCHER, K. J. A Pentecostal Hermeneutic for the Twenty-First Century: Spirit, Scripture, and Community. London: T\&T Clark, 2004.

ASSEMBLEIAS DE DEUS. Declaração de fé das Assembleias de Deus. Rio de Janeiro: CPAD, 2017.

BONINO, J. M. Rostos do protestantismo latino-americano. São Leopoldo: Sinodal, 2003.

BOSCH, D. J. Missão transformadora: mudanças de paradigmas na teologia da missão. 2.ed. São Leopoldo: Sinodal, 2007.

CAMPOS, B. O princípio da pentecostalidade: hermenêutica, história e teologia. São Paulo: Recriar, 2018a.

CAMPOS, B. Hermenêutica do Espírito: uma proposta para hermenêutica pentecostal. São Paulo: Recriar, 2018b.

COMISSÃO INTERNACIONAL DE DIÁLOGO CATÓLICO-PENTECOSTAL. Tornar-se cristão: inspiração da Escritura e dos textos da Patrística com algumas 
reflexões contemporâneas. Relatório da Quinta Fase do Diálogo Internacional entre algumas lideranças e Igreja Pentecostais Clássicas e a Igreja Católica (1998-2006). Brasília: CNBB, 2010.

CONSTITUIÇÃO Pastoral Gaudium et Spes. Documentos do Concílio Ecumênico Vaticano II. São Paulo: Paulus, 1997.

COX, H. Fire From Heaven: the Rise of Pentecostal Spirituality and the Reshaping of Religion in the Twenty-First Century. Boston: Addison-Wesley Publishing Company, 1995.

DAYTON, D. Raízes Teológicas do Pentecostalismo. Natal: Carisma, 2018.

DUFFIELD, G. P.; VAN CLEAVE, N. M. Fundamentos de teología pentecostal. 2.ed. Bogotá: Desafío, 2002.

EVDOKIMOV, P. O Espírito Santo na tradição ortodoxa. São Paulo: AM, 1996.

GILBERTO, A. Pneumatologia - A doutrina do Espírito Santo. In: GILBERTO, A. (Ed.). Teologia sistemática pentecostal. Rio de Janeiro: CPAD, 2008. p. 171-230.

GILBERTO, A. Verdades pentecostais. 2 ed. Rio de Janeiro: CPAD, 2019.

HORTON, S. M. (Ed.). Teologia sistemática: uma perspectiva pentecostal. 3 ed. Rio de Janeiro: CPAD, 1997.

KARKKAINEN, V. M. Pneumatology: the Holy Spirit in Ecumenical, International, and Contextual Perspective. Grand Rapids: Baker Academic, 2002.

KEENER, C. S. O Espírito nos Evangelhos e em Atos: pureza e poder divino. São Paulo: Vida Nova, 2018a.

KEENER, C. S. O Espírito na Igreja: o que a Bíblia ensina sobre os dons. São Paulo: Vida Nova, 2018b.

LAND, S. J. Pentecostal Spirituality: a Passion for the Kingdom. New York: Sheffield Academic, 1993.

LIBANIO, J. B. A Religião no início do milênio. São Paulo: Loyola, 2002.

MAÇANEIRO, M. "Há diversidade de dons, mas o Espírito é o mesmo" (1Co 12,4). Relatório da $6^{\text {a }}$ fase do Diálogo Internacional Católico-Pentecostal: tópicos fundamentais. Revista Medellín, v. XLIII, n. 169, p. 675-702, 2017.

MACCHIA, F. D. Baptized in the Spirit: a Global Pentecostal Theology. Grand Rapids: Zondervan, 2006.

McGEE, G. (Ed.). Evidência inicial: perspectivas históricas e bíblicas sobre a doutrina pentecostal do batismo no Espírito. Natal: Carisma, 2017.

McLEAN, M. D. O Espírito Santo. In: HORTON, S. M. Teologia sistemática: uma perspectiva pentecostal. 3 ed. Rio de Janeiro: CPAD, 1997. p. 383-404.

MENZIES, R. P.; MENZIES, W. W. No poder do Espírito: fundamentos da experiência pentecostal - um chamado ao diálogo. São Paulo: Vida, 2002.

MENZIES, R. P. Pentecostes: essa é a nossa história. Rio de Janeiro: CPAD, 2016. 
MIRANDA, M. F. Inculturação da fé: uma abordagem teológica. São Paulo: Loyola, 2001.

MIRANDA, M.F. A salvação de Jesus Cristo: a doutrina da graça. São Paulo: Loyola, 2004.

MIRANDA, M. F. A Igreja numa sociedade fragmentada: escritos eclesiológicos. São Paulo: Loyola, 2006.

MIRANDA, M. F. Em vista da Nova Evangelização. Perspectiva Teológica, Belo Horizonte, v. 45, n. 125, p. 13-34, jan./abril 2013.

MOLTMANN, J. Espírito da vida: uma pneumatologia integral. Petrópolis: Vozes, 1999.

MOLTMANN, J. A fonte da vida: o Espírito Santo e a teologia da vida. São Paulo: Loyola, 2002.

NIEBUHR, H. Richard. Cristo e cultura. Rio de Janeiro: Paz e Terra, 1967.

OLIVEIRA, D. M. Salvação, acolhida do ser humano e a obra do Espírito Santo. Atualidade Teológica, Rio de Janeiro, v. 17, n. 43, p. 39-69, jan./abril 2013.

OLIVEIRA, D. M. A pneumatologia de Lutero: uma aproximação. Reflexus, Vitória, v. 11, n. 17, p. 161-178, 2017a.

OLIVEIRA, D. M. Os Pentecostais, o Espírito Santo e a Reforma. Pistis E Práxis, Curitiba, v. 9, p. 539-553, 2017b.

OLIVEIRA, D. M. O movimento pentecostal: características e desafios. In: CAVALCANTE, R.; OLIVEIRA, D. M.; TERRA, K. R. C. Experiência e hermenêutica pentecostal. Rio de Janeiro: CPAD, 2018.

OLIVEIRA, D. M.; ROCHA, A. R. Pentecostalismo e empoderamento de identidades marginalizadas. Pistis E Práxis, Curitiba, v. 10, p. 722-741, 2018.

PALMA, A. D. O batismo no Espírito Santo e com fogo: os fundamentos bíblicos e a atualidade da doutrina pentecostal. Rio de Janeiro: CPAD, 2014.

ROBECK JR., C. M. William J. Seymor e a "evidência bíblica". In: McGEE, G. (Ed.). Evidência inicial: perspectivas históricas e bíblicas sobre a doutrina pentecostal do batismo no Espírito. Natal: Carisma, 2017. p. 101-127.

ROCHA, A. Espírito Santo: aspectos de uma pneumatologia solidária à condição humana. São Paulo: Vida, 2008.

RUTHVEN, J. M. Sobre a cessação dos charismata: a polêmica cessacionista sobre os milagres pós-bíblicos. Natal: Carisma, 2017.

SEYMOUR, W. J. O Avivamento da Rua Azuza. Rio de Janeiro: CPAD, 2001.

SMITH, J. K. A. What Hath Cambridge to do with Azusa Street? Radical Orthodoxy and Pentecostal Theology in Conversation. Pneuma, Leiden, v. 25, n. 1, p. 97-114, 2003.

TANCARA CHAMBE, J. J. Teología pentecostal popular: la fe en comunidades periurbanas y andinas. La Paz, Bolívia: ISEAT, 2011.

TERRA, K. R. C. Epistemologia pentecostal e presença política. RBHR, ANPUH, Maringá, Ano XIII, n. 37, 2020, p. 43-57. 
TILLICH, P. Teologia da cultura. São Paulo: Fonte, 2009.

WEGNER, U. Batismo no Espírito Santo (BES): avaliação de sua compreensão dentro do pentecostalismo. In: WACHHOLZ, W. (Coord.). Batismo: teologia e prática. São Leopoldo: EST, 2006. p. 7-39.

WILLIAMS, J. R. Teologia sistemática: uma perspectiva pentecostal. São Paulo: Vida, 2011.

WYCKOFF, J. W. O batismo no Espírito Santo. In: HORTON, S. M. Teologia sistemática: uma perspectiva pentecostal. 3.ed. Rio de Janeiro: CPAD, 1997. p. 431-463.

YONG, A. The Spirit Poured Out on All Flesh: Pentecostalism and the Possibility of Global Theology. Grand Rapids: Baker Academic, 2005.

YONG, A. Spirit-Word-Community. Eugene: Wipf \& Stock Publishers, 2006.

Artigo submetido em 08.05.2020 e aprovado em 05.08.2020.

David Mesquiati de Oliveira é Doutor em Teologia (PUC-Rio, 2013), docente no Programa de Pós-Graduação em Ciências da Religião da Faculdade Unida de Vitória, coordenador da RELEP Brasil (Rede Latino-americana de Estudos Pentecostais). Tem estudos de pós-doutorado na PUC-Rio, na Faculdade EST e no Princeton Theological Seminary. Orcid.org/0000-00025091-9563. E-mail: david@fuv.edu.br

Endereço:Av. Saturnino Rangel Mauro, 6122, Ap. 1404

Bairro Praia de Itaparica

29102-036 Vila Velha - ES 